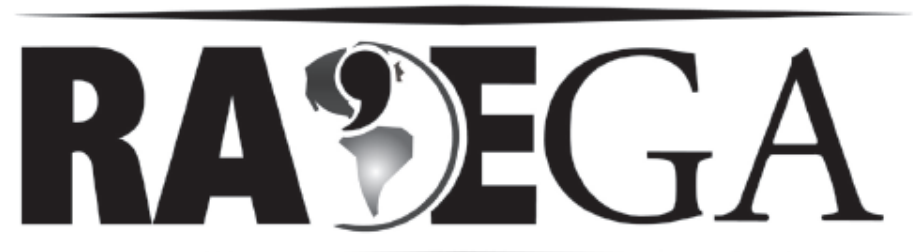

O ESPAÇO GEOGRÁFICO EM ANÁLISE

\title{
CARTOGRAFIA GEOMORFOLÓGICA COMO SUBSÍDIO PARA A ANÁLISE DAS INTERFERÊNCIAS DO USO DA TERRA NO DESENCADEAMENTO DOS PROCESSOS EROSIVOS: UM ESTUDO EM ÁREA CANAVIEIRA.
}

\section{THE GEOMORPHOLOGIC CARTOGRAPHY AS A SUBSIDY TO ANALYSE THE LAND USE INTERFERENCES IN ACTIVATING EROSION PROCESSSES: A STUDY IN A SUGARCANE AREA.}

\author{
Alan Silveira $^{1}$
}

Cenira Maria Lupinacci da Cunha

\begin{abstract}
Resumo
O trabalho teve como objetivo principal analisar a dinâmica geomorfológica e sua relação com a interferência e apropriação humana do relevo, mediante a interpretação de forma integrada, perante uma abordagem sistêmica, de documentos cartográficos elaborados a partir de técnicas da cartografia geomorfológica e de uso da terra. Por meio de pares estereoscópicos de fotografias aéreas foram elaborados as Cartas Geomorfológica e de Uso da Terra, respectivamente fundamentadas nos procedimentos técnicos de Tricart (1965) e Ceron e Diniz (1966). A unidade de análise da pesquisa refere-se à Bacia do Ribeirão Tijuco Preto (SP) que se encontra posicionada na Província

\footnotetext{
${ }^{1}$ Geógrafo (bacharel e licenciado) e Mestre em Geografia (Organização do Espaço). Doutorando do Programa de Pós-Graduação em Geografia da UNESP - Campus de Rio Claro. silveira 81@yahoo.com.br

${ }^{2}$ Doutora em Geociências e Meio Ambiente, Professora na UNESP, campus de Rio Claro. cenira@rc.unesp.br
} 
Geomorfológica da Depressão Periférica Paulista, estabelecendo-se entre as latitudes $22^{\circ} 42^{\prime} 17^{\prime \prime}$ e $22^{\circ} 51^{\prime \prime} 36^{\prime \prime} \mathrm{S}$, e as longitudes $47^{\circ} 30^{\prime} 30^{\prime \prime}$ e $47^{\circ} 37^{\prime} 03^{\prime \prime}$. De forma geral, pôde-se constatar que esta Bacia vem sofrendo o desencadeamento de processos erosivos lineares, onde foram mapeados em grande número sulcos erosivos, ravinamentos e voçorocamentos, além de inúmeras rupturas de declive. Tais processos estão associados a uma conjunção de condicionantes, onde o condicionante antrópico está majoritariamente representado pela monocultura canavieira e pela urbanização, sendo agentes cruciais no desencadeamento dos processos erosivos e na interferência direta na dinâmica do escoamento fluvial e pluvial da Bacia do Ribeirão Tijuco Preto.

Palavras chave: dinâmica geomorfológica, uso da terra, processo erosivo e monocultura canavieira.

\section{Abstract}

This study aimed at analyzing the geomorphologic dynamics and its relationship to human interference and ownership of relief, towards a systemic approach, through the interpretation, in an integrated manner, of cartographic documents made from techniques of geomorphologic cartography and of land use. By stereoscopic pairs of aerial photographs, it was prepared the Geomorphological Map and the Land Use Map, respectively based on Tricart's (1965) and Ceron and Diniz's (1966) technical procedures. The unit of the research analysis refers to the basin of Tijuco Preto Streamlet (SP) which is located at the Geomorphological Province of São Paulo state Peripheral Depression between latitudes 22042'17"

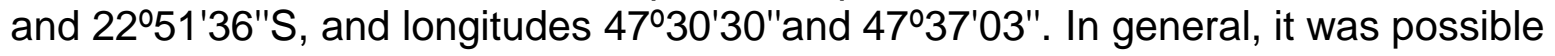
to notice that this basin has been experiencing linear erosion processes, where it was mapped many erosion furrows, grooving and creeping, besides several slope breaks. These processes are associated with a conjunction of circumstances, and the anthropic one is mostly represented by sugarcane monoculture and by urbanization, which are crucial agents in activating erosion processes and in direct interfering on the dynamics of river and rain flow at the basin of Tijuco Preto Streamlet.

Key words: geomorphologic dynamics, land use, erosion process and sugarcane monoculture.

\section{INTRODUÇÃO.}

A compreensão da complexidade dos sistemas naturais, que apresentam dinâmicas próprias de fluxos de energia e matéria, tem sido um dos grandes desafios da ciência, sobretudo a partir de sua consolidação como ciência 
moderna. Com o advento das sociedades urbano-industriais, o elevado poderio tecnológico, proporcionou a configuração de um sistema próprio da sociedade, caracterizado como um sistema antropizado, que interfere diretamente na dinâmica do sistema natural.

A relação entre o sistema natural e o sistema antropizado, que se reflete nos diversos padrões de organizações espaciais, tomou proporções relevantes no âmbito da ciência geográfica, atribuindo como campo de seu conhecimento o entendimento dos fenômenos resultantes da interação entre sociedade e natureza, ou entre o sistema natural e o sistema antrópico, refletindo diretamente nas organizações espaciais.

Inerente ao conhecimento geográfico, a Geomorfologia, que tem especial atenção às formas e processos do relevo, vem contribuindo significativamente para a compreensão da relação entre o social e o natural, haja vista, que na superfície terrestre se consolidam e materializam as atividades e produção dos espaços humanizados.

Assim, o relevo é um componente da natureza, sendo produto de fluxos internos e externos de energia, resultando em formas as quais oferecem sustentáculo para arranjos espaciais de produção humana (Ross, 2006). Logo, a Geomorfologia também tem fundamental importância na compreensão da relação sociedade - natureza, visto que, é no relevo, parte integrante do sistema natural, que as sociedades organizam e produzem seus espaços. Ross (2006, p.9), argumenta que:

A Geomorfologia é a disciplina das ciências da Terra mais diretamente utilizada e proporciona suporte absoluto as atividades humanas. Nesse sentido, destaca-se que o relevo da superfície terrestre é o "piso", o "chão", onde a humanidade constrói e desenvolve suas atividades, produz, organiza e reorganiza seus espaços territoriais. A Geomorfologia ajuda a explicar como os espaços territoriais terrestres se organizam por meio das ações humanas. 
Nestes termos, a Geomorfologia, pode vir a contribuir com a representação das interferências humanas no meio natural, em especial no relevo, por meio do fornecimento de documentos cartográficos derivados do desenvolvimento da cartografia geomorfológica. Esta, associada a estudos de natureza da Geografia Física Aplicada européia, sobretudo do leste europeu e francesa (ROSS, 2001), tem como fundamento subsidiar o planejamento e ordenamento das ações do homem no meio físico, com atenção especial a representação e espacialização das formas de relevo. Sobre a contribuição da cartografia geomorfológica no contexto da Geomorfologia, Cunha, Mendes e Sanchez (2003a, p.1), registram que:

A geomorfologia, entendida como o estudo das formas de relevo e dos processos responsáveis por sua elaboração, tem na cartografia geomorfológica um dos mais importantes veículos de comunicação e análise dos resultados obtidos. Extensas análises descritivas das formas, idade e gênese do relevo tornam-se muito mais ricas e lógicas quando acompanhadas por documentos cartográficos nos quais estas estejam espacializadas.

Propôs-se, portanto para este trabalho, a elaboração de documentos cartográficos que contemplassem a análise geomorfológica e do uso da terra, considerando que a representação cartográfica do relevo tem papel indispensável na abordagem do planejamento ambiental, visto que é sobre as feições geomorfológicas que se localizam e se desenvolvem as atividades humanas (CUNHA, MENDES e SANCHES, 2003b). Logo, o modelado terrestre surge como elemento do sistema ambiental físico e é fator condicionante para a realização das atividades humanas e organizações espaciais (CHRISTOFOLETTI, 1995).

A unidade selecionada para estudo corresponde a Bacia do Ribeirão Tijuco Preto (SP), compreendendo-a como um sistema controlado, já que as atividades antrópicas se realizam sem planejamento, via expansão urbana das cidades de 
Piracicaba (SP) e Rio das Pedras (SP) e, sobretudo pelo cultivo extensivo da monocultura canavieira, contribuindo para o desenvolvimento de processos erosivos, conforme registros "in loco".

Assim a pesquisa teve como objetivo principal a analise a dinâmica geomorfológica, considerando os condicionantes naturais do meio físico em sua relação com as interferências promovidas pela apropriação humana do relevo, mediante a interpretação de forma integrada dos documentos cartográficos elaborados a partir de técnicas da cartografia geomorfológica e de uso da terra.

A Carta Geomorfológica, embasada em técnicas de Tricart (1965), representa as formas de relevo, possibilitando, através de sua análise, inferir os processos geomórficos e assim espacializar a dinâmica geomorfológica atuante na unidade mapeada. A Carta de Uso da Terra, seguindo as recomendações técnicas de Ceron e Diniz (1966), espacializa os padrões de uso e ocupação resultantes da produção humana.

A essas informações, foram associadas às características litológicas, pedológicas e climáticas, registradas em materiais cartográficos e bibliográficos pesquisados, fundamentais, perante uma abordagem sistêmica, para analise integrada do meio físico sob intervenção antrópica. Tais informações coletadas, associadas às informações provenientes dos produtos cartográficos elaborados, promoveram subsídio à análise das interferências das atividades humanas no quadro geomorfologico, sobretudo no que tange ao desencadeamento dos processos erosivos.

Procurou, portanto, este trabalho contemplar, diante dos pressupostos geográficos e geomorfológicos, a relação estabelecida entre o sistema natural e o sistema antrópico mediante adoção da abordagem sistêmica. Esta possibilita a análise integrada dos componentes do meio físico, bem como o entendimento das interferências promovidas pelo homem, garantindo uma visão da relação interativa, interdependente e dinâmica entre os elementos que regem as organizações espaciais. 


\section{MÉTODO E TÉCNICAS CARTOGRÁFICAS.}

\section{O Método.}

A fundamentação teórica da pesquisa esteve associada à Teoria Geral dos Sistemas aplicada à ciência geográfica, como subsídio ao procedimento analítico geomorfológico. Concebe-se esta Teoria como 0 método da pesquisa. Christofoletti, (1997, apud VICENTE e PEREZ FILHO, 2003, p.333), ressaltou a importância de tal método definindo sua utilidade para a análise geomorfológica:

A abordagem sistêmica surge como plenamente adequada à análise geomorfológica, pois considera que um sistema é constituído por um conjunto de elementos interconectados que funcionam compondo uma complexa entidade integrada.

Chorley e Kennedy (1971), levando em consideração o critério estrutural, propuseram uma classificação distinguindo onze tipos de estruturas dos sistemas. Entre estas, Christofoletti (1999), considerando o campo da Geografia Física e da Geomorfologia, referencia quatro tipos de estruturas como sendo as mais relevantes, a saber: morfologia (formas), em seqüência (processos), processosrespostas (formas-processos/processos-formas) e controladas (processo-resposta sob interferência antrópica) (figura 1).

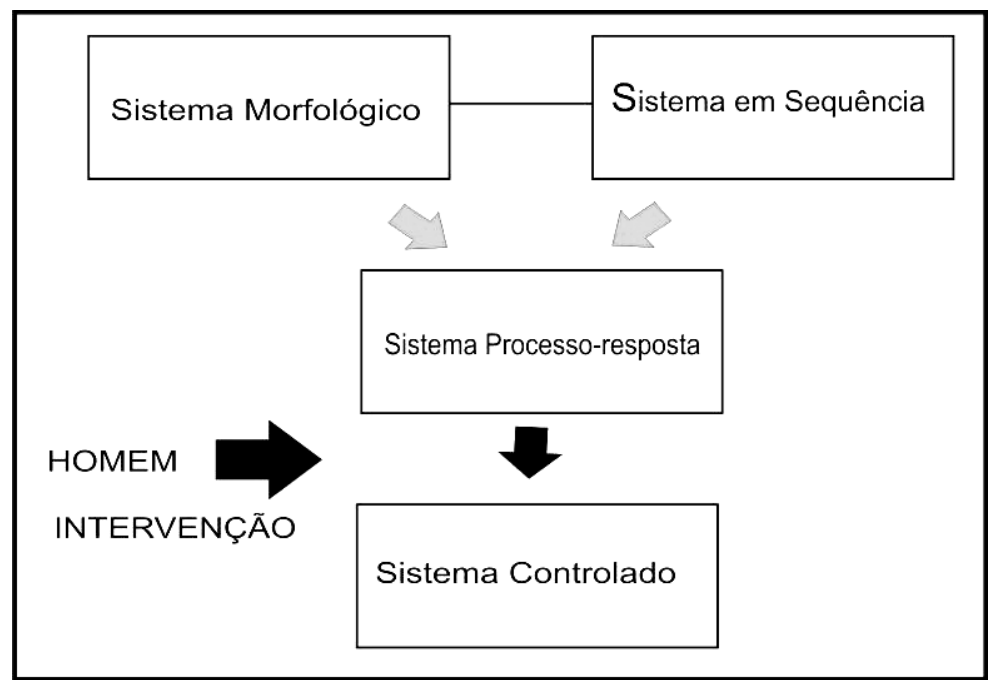

FIGURA 1: Localização da Bacia do Ribeirão Tijuco Preto (SP). Organização: Silveira, A. 
O autor chama atenção para, ao invés de se usar as denominações da complexidade da composição estrutural como sendo categorias de sistemas, conforme utilizados por Chorley e Kennedy (1971), utilizar esta nomenclatura para distinguir categorias no procedimento analítico:

Dessa maneira, realiza-se a análise morfológica de sistemas, a análise dos processos em sistemas e a análise da interação formas e processos em sistemas. Em conseqüência, a quarta categoria encontra-se relacionada com a avaliação dos sistemas e atividades de planejamento, delineando os procedimentos de interferência (CHRISTOFOLETTI 1999, p.7).

Visto isso, esta pesquisa teve por finalidade a análise do sistema geomorfológico (processo-resposta), inerente ao quadro natural, com função aberta, caracterizando-se por constantes trocas e fluxos de matéria e energia, sob as interferências antrópicas. Estas, alterando a dinâmica natural, permitiu a implementação do quarto nível de análise, ou seja, com a avaliação do sistema para fins de planejamento.

Dessa forma, a bacia hidrográfica aqui estudada é entendida como um sistema geomorfológico controlado, haja vista as interferências antrópicas a esta associada, sobretudo relacionada à retirada da cobertura vegetal, substituída em maioria pelo cultivo da monocultura canavieira, bem como pela urbanização.

Fez-se necessário, portanto, perante a uma abordagem sistêmica, o levantamento de condicionantes do meio físico e das atividades antrópicas, para a análise da dinâmica geomorfológica da unidade de estudo. A esse respeito, Cunha (2001, p.35) ressalta que:

Com relação à Geomorfologia, verifica-se que é impossível compreender o relevo sem considerar os fluxos de matéria e energia responsáveis por sua gênese e esculturação. Desse modo, entendendo-se as formas de relevo como fruto da interação da estrutura geológica, do clima, atual e passado, e atualmente, da atividade antrópica, cujas relações interferem nas características pedológicas e na cobertura vegetal, verifica-se que a visão sistêmica possibilita estabelecer e analisar tais inter-relações, assim como compreender os vínculos de dependência entre esses fatores. 
Com o intuito da promoção de uma análise integrada do meio físico sob interferência das atividades antrópicas, principalmente no que tange ao desencadeamento de processos erosivos, propôs-se conforme outrora mencionado, a compilação de documentos cartográficos e bibliográficos geológicos e pedológicos, bem como de informações climáticas, além da produção de documentos cartográficos relativos à Carta Geomorfológica e a Carta de Uso da Terra.

\section{As Técnicas Cartográficas.}

A Carta Geomorfológica de detalhe foi elaborada segundo os procedimentos técnicos propostos por Tricart (1965), que adota como fonte de dados pares estereoscópicos de fotografias aéreas. Dessa maneira, foram fotointerpretadas, mediante a utilização dos estereoscópios de bolso e de espelho, fotografias aéreas na escala aproximada de 1:25.000, para o cenário do ano de 1995.

Tricart (1965) destaca que as Cartas Geomorfológicas de detalhe devem contemplar quatro tipos de informação, sendo estas referentes à morfometria, morfografia, morfogênese e cronologia. Nesta pesquisa deu-se ênfase aos dados morfográficos visto que, através destes, é possível identificar feições de relevo que indicam processos erosivos os quais constituem o foco principal do trabalho.

A morfometria foi contemplada em outros documentos cartográficos, denominados por morfométricos, desenvolvidos em outro momento do projeto de pesquisa. Já a cronologia avaliou-se somente em termos relativos, considerando a dificuldade de obtenção destes dados, enquanto a morfogênese pode-se averiguar através do agrupamento dos dados morfográficos como sugerido pelo autor.

Quanto à simbologia, verificou-se que Tricart (1965) apresenta uma ampla concepção de símbolos, tanto para as feições naturais, quanto para as antrópicas. 
No entanto, esta proposta não contempla símbolos para as formas de vertentes, tendo sido necessário utilizar simbologias para a identificação das vertentes convexas, côncavas, retilíneas e irregulares, dada à importância dessas na interpretação do quadro geomorfológico mapeado. Para estas feições adotou-se a simbologia de Verstappen e Zuidam (1975).

Assim, a proposta de Tricart (1965), quanto à cartografia geomorfológica de detalhe, complementadas pela simbologia de Verstappen e Zuidam (1975), contempla as formas de relevo através da simbologia e os processos a partir do agrupamento destas, como também a ação humana interferindo no modelado terrestre, possibilitando a análise dos sistemas controlados (CUNHA, 2001).

Feita a fotointerpretação em papel "overlay", os mesmos foram escaneados e posteriormente transferidos para edição no Corel Draw 13. Feita a edição da Carta Geomorfológica, dirigiu-se ao campo para aferir os fenômenos mapeados, bem como para registrar aqueles não apontados no processo de fotointerpretação.

A Carta de Uso da Terra foi também elaborada mediante a fotointerpretação de fotografias aéreas do ano de 1995, a partir do uso do estereoscópio. Teve como referencial técnico para a identificação da tipologia de uso e ocupação da superfície terrestre os procedimentos apontados por Ceron e Diniz (1966), principalmente aqueles relacionados aos usos agrícolas. Foram mapeadas as seguintes categorias de uso e ocupação da terra: cana-de-açúcar, pastagem, área construída, área urbana, mata e reflorestamento.

Elaborado o documento cartográfico proposto, foram realizados permanentes investidas ao campo para aferir e atualizar as informações mapeadas na Carta de Uso da Terra. Tais atualizações foram realizadas por meio da rica malha viária pavimentada e não pavimentada disposta na área de estudo para escoamento da produção canavieira, com base nos compartimentos de análise da pesquisa, como registrado na figura 5 (Análise dos Resultados). $O$ uso do GPS e dos registros fotográficos foram imprescindíveis para esta atualização. 
Por fim, as informações geológicas, pedológicas e climáticas foram compiladas a partir de materiais bibliográficos e cartográficos pesquisados. Embora as escalas dos materiais cartográficos de geologia e solos sejam pequenas, tomou-se a providência de aferir tais informações em campo, para posterior correlação com as informações dos produtos cartográficos elaborados representados pelas Cartas Geomorfológica e de Uso da Terra em escalas de maior detalhe. As informações sobre estas características físicas da Bacia permitiram compreender as fragilidades naturais do sistema e, principalmente, verificar que certos fenômenos erosivos estão vinculados mais nitidamente as ações antrópicas do que a estas características naturais.

\section{LOCALIZAÇÃO E CARACTERIZAÇÃO DA ÁREA DE ESTUDO.}

A Bacia Hidrográfica do Ribeirão Tijuco Preto, está localizada no interior do estado de São Paulo e apresenta área de $85,15 \mathrm{Km}^{2}$, sendo que $43,94 \%$ de sua extensão pertencem ao município de Piracicaba (SP), enquanto 56,06\% inseremse no município de Rio das Pedras (SP). O Ribeirão Tijuco Preto é afluente direto da margem esquerda da média bacia do Rio Piracicaba (figura 2), encontrando-se posicionado, do ponto de vista geomorfológico, na Província da Depressão Periférica Paulista, estabelecendo-se aproximadamente entre as latitudes

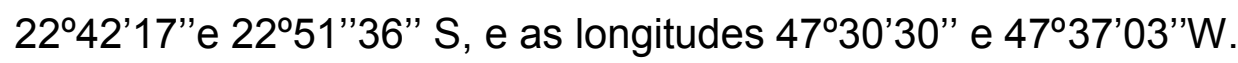

Penteado (1976) argumenta que a Depressão Periférica Paulista está esculpida predominantemente em sedimentos do Paleozóico, correspondendo a uma área deprimida embutida entre as escarpas avançadas da zona das Cuestas e o Planalto Cristalino Atlântico, com topografia pouco acidentada numa faixa de cerca de 450 quilômetros de comprimento, de norte a sul, e de aproximadamente 100 quilômetros de largura média. 


\section{Localização da Bacia do Ribeirão Tijuco Preto (SP)}

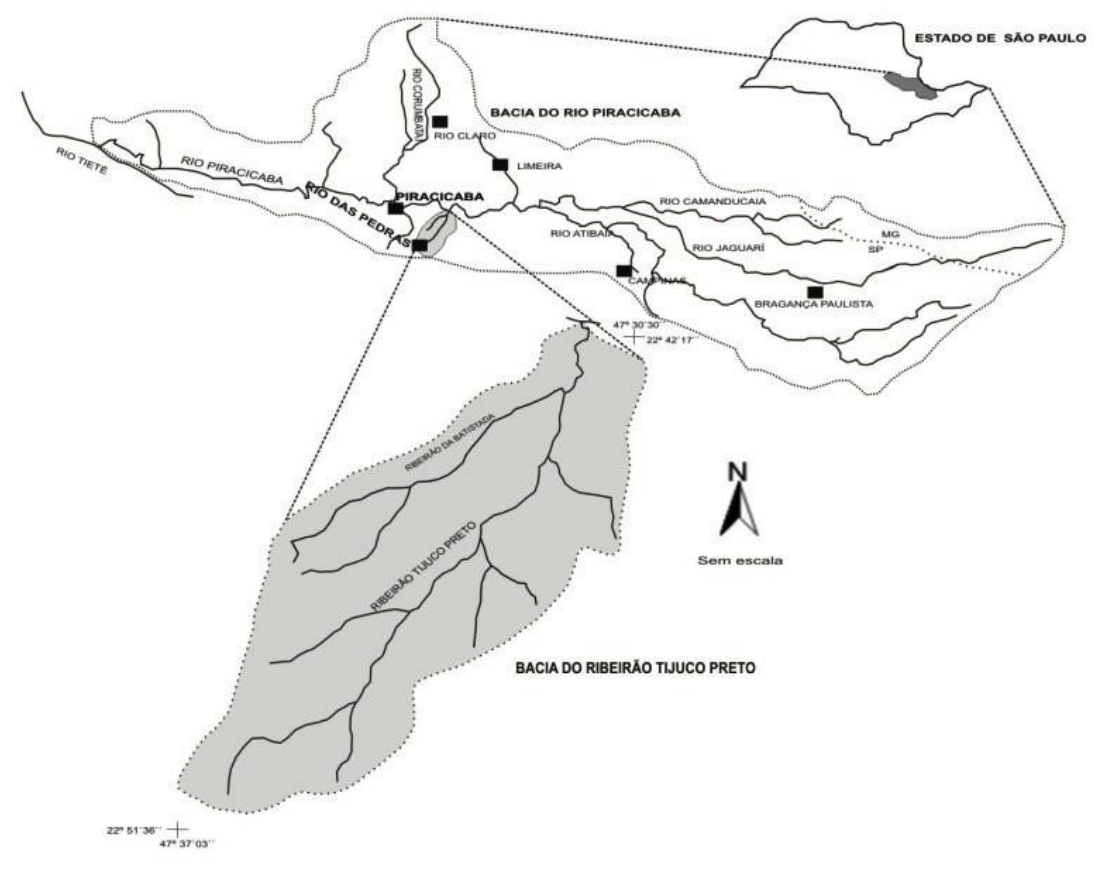

FIGURA 2: Localização da Bacia do Ribeirão Tijuco Preto (SP). Organização: Silveira, A.

Almeida (1964), apoiando-se em Deffontaines (1935), compartimentando o relevo paulista, subdividiu a Província da Depressão Periférica em três zonas: do Médio-Tietê, do Mogi-Guaçu e do Paranapanema, delimitadas segundo os divisores de água desses rios, estando a Bacia do Tijuco Preto calcada na primeira zona citada.

A Zona do Médio-Tietê é constituída principalmente por rochas sedimentares com áreas expressivas de intrusões de rochas básicas, que geram reflexos em sua topografia (IPT, 1981a). De acordo com mapeamento realizado pelo IGG (1966) e IPT (1981b) encontram-se sob a área de estudo tanto litologias Paleozóicas, referentes ao Grupo Tubarão e Passa Dois, como Mesozóicas, referentes ao grupo São Bento (figura 3). 
O Grupo Tubarão se faz presente através das Formações Itararé, do Carbonífero Superior e Tatuí, do Permiano Médio. A Formação Iratí, do Permiano Superior, é representante do Grupo Passa Dois, enquanto o Grupo São Bento se faz presente pelas Formações Botucatu e Serra Geral, ambas do Jurássico.

As litologias citadas estão sobrepostas, segundo a Carta Pedológica Semidetalhada do IAC (1989), na Bacia do Ribeirão Tijuco Preto, por solos do tipo Latossolos, Terra Roxa, Litólicos e Podzólicos. Atualizando essas informações a partir da classificação de solos estabelecida pela EMBRAPA (1999), a área fica caracterizada pela presença de: Latossolos, Nitossolos, Neossolos e Argissolos (figura 4).

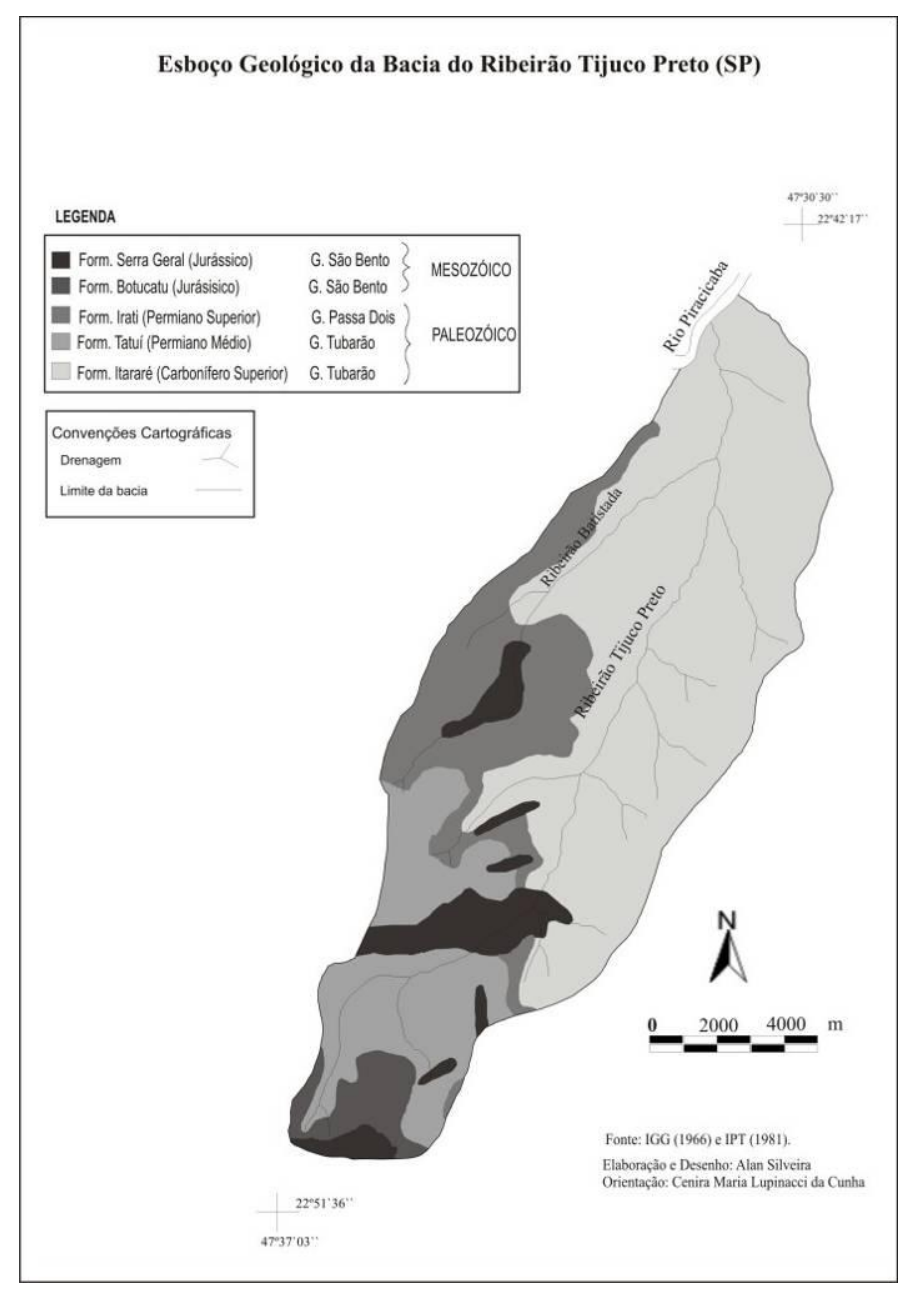

FIGURA 3: Esboço Geológico da Bacia do Ribeirão Tijuco Preto (SP). 


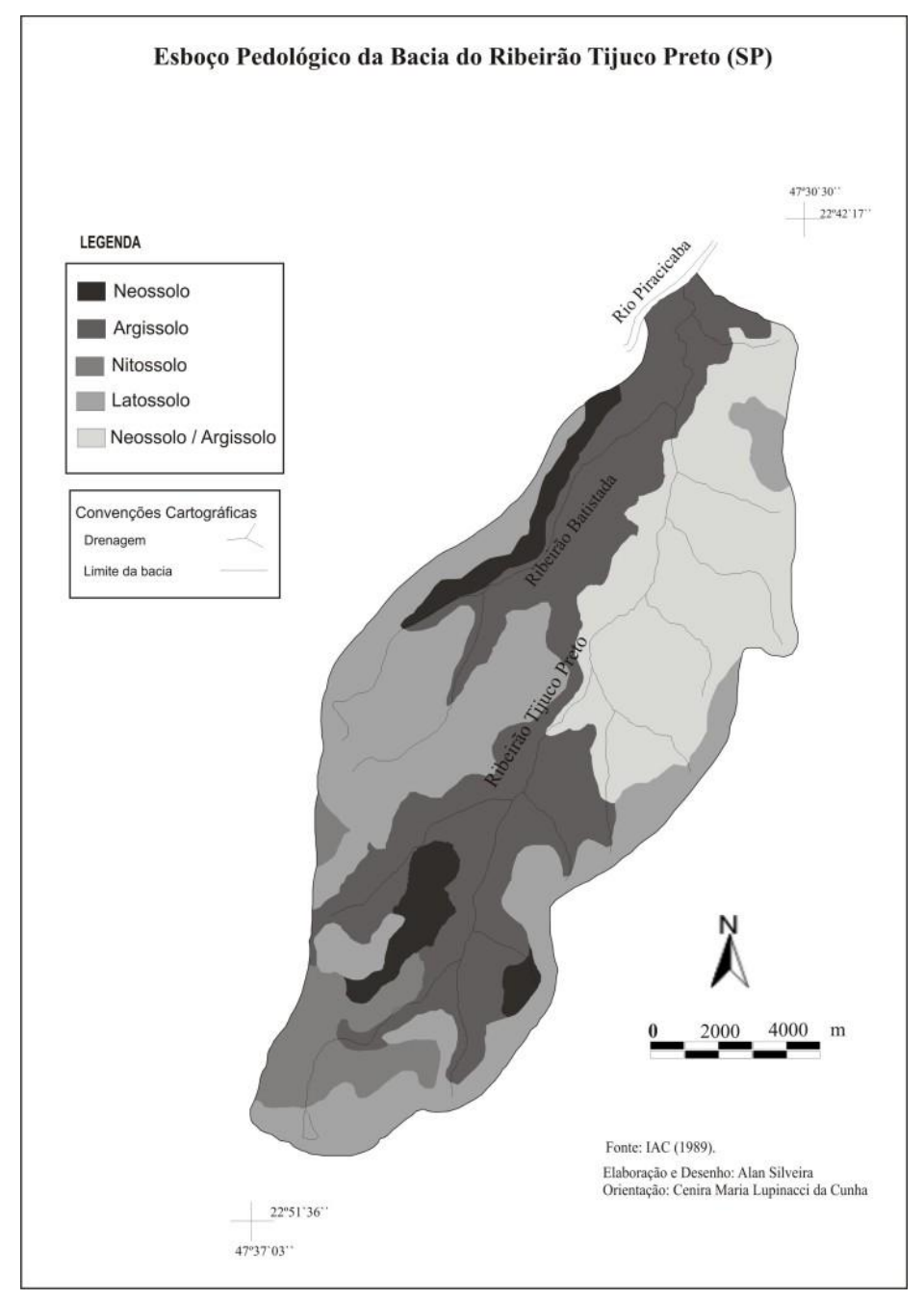

FIGURA 4: Esboço Pedológico da Bacia do Ribeirão Tijuco Preto (SP).

As condições pedológicas mencionadas estão sujeitas, conforme dados obtidos por Silva e Pfeifer (1998) para o período de 1985 a 1994, a um regime pluviométrico de duas estações bem definidas, uma chuvosa de verão, que se estende de outubro a abril e outra, seca de inverno se estendendo de maio a setembro. Dessa forma, de acordo com a classificação de Koppen, a região de Piracicaba, onde se insere a Bacia de estudo, apresenta um clima do tipo Cwa, caracterizando-se como mesotérmico úmido subtropical de inverno seco (INSTITUTO FLORESTAL, 1999). 
As condições físicas apresentadas, compreendendo o sistema natural, estão submetidas à ação permanente do sistema antrópico. O agravante preponderante em termos de uso e ocupação desordenado nesta Bacia vincula-se a monocultura canavieira, bem como a expansão urbana de Rio das Pedras e Piracicaba. Em mapeamento do uso da terra da Bacia do Ribeirão Tijuco Preto realizado por Prochnow (1994) para o cenário do ano de 1990, registrou-se a presença da cana-de-açúcar em $63,6 \%$ da extensão total da Bacia. Nos dias atuais, registros "in loco" permitem afirmar que os percentuais registrados em 1990 sofreram elevação, haja vista o desenvolvimento do setor sucroalcooleiro regional e sua demanda por matéria-prima.

\section{ANÁLISE DOS RESULTADOS.}

Para uma melhor apresentação da análise dos dados obtidos com os produtos cartográficos compilados e elaborados sobre a Bacia do Ribeirão Tijuco Preto, foi elaborada uma compartimentação da Bacia em quatro grandes setores (figura 5), os quais foram definidos também de acordo com as características morfológicas peculiares a cada setor. Assim, discute-se a Alta Bacia, que é o setor das nascentes; a Média Bacia Leste e Média Bacia Oeste, subdivididas pelo extenso interflúvio sub-tabular entre o Ribeirão Tijuco Preto e seu principal afluente, o Ribeirão Batistada; e a Baixa Bacia, do encontro do Ribeirão Tijuco Preto com o Ribeirão Batistada ao deságüe no Rio Piracicaba.

O setor da Alta Bacia, do ponto de vista morfológico, representado na Carta Geomorfológica (figura 6), apresenta colinas de topos convexos, estando as nascentes entalhadas em formas concavizadas, semelhantes a "anfiteatros". Embora as condições pedológicas majoritárias não denotem potencial ao desencadeamento de processos erosivos, pela presença de solos em estágio avançado de intemperização, representados pelos Nitossolos e Latossolos, tais concavidades estão envolvidas por rupturas de declive, apresentando formas erosivas associadas, sobretudo a sulcos erosivos. 


\section{Compartimentos da Bacia do Ribeirão Tijuco Preto (SP)}

\section{LEGENDA}

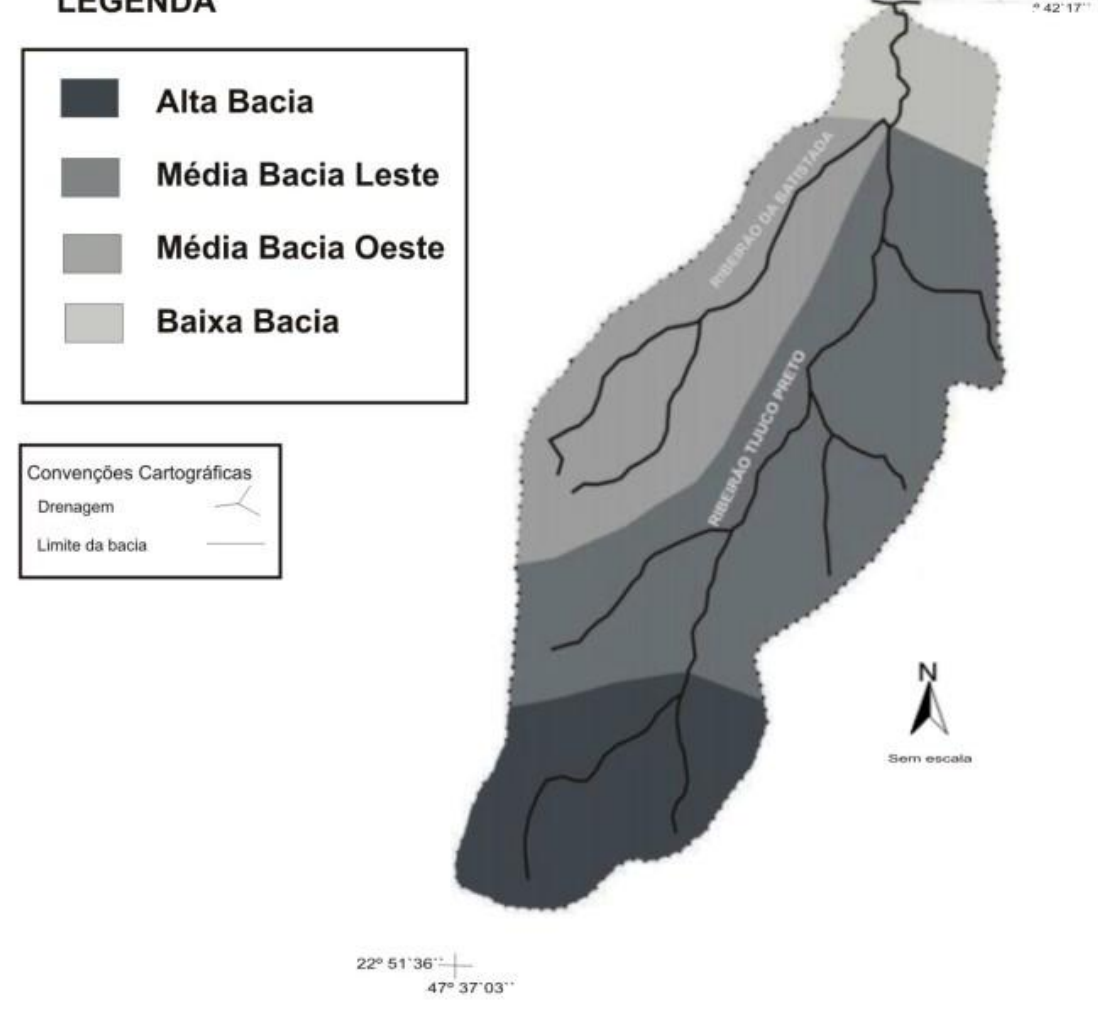

FIGURA 5: Compartimentos da Bacia do Ribeirão Tijuco Preto (SP). Organização: Silveira, A.

Estes foram registrados em áreas canavieiras que, mesmo com a presença de terraços agrícolas, não são suficientes para a contenção de processos erosivos lineares. Assim, as variáveis desencadeadoras destes processos, podem ser atreladas as ações antrópicas vinculadas a monocultura canavieira, que em grande parte do ano permanece desprovida de cobertura vegetal, estando a camada pedológica, permanentemente removida pelo arado, aos condicionantes pluviométricos de um clima mesotérmico úmido subtropical de inverno seco. Ou seja, com índices pluviométricos elevados, sobretudo no verão. 


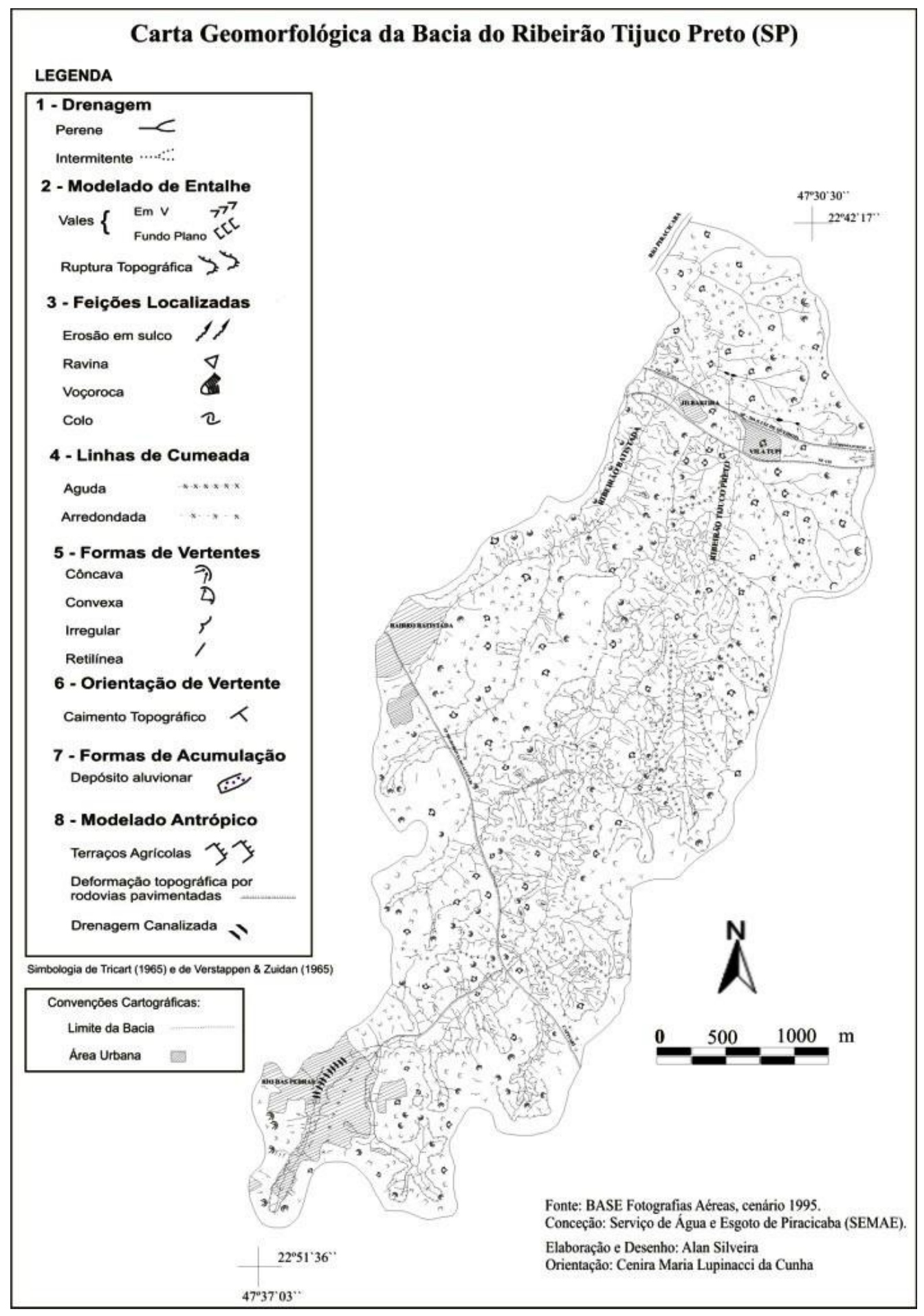

FIGURA 6: Carta Geomorfológica da Bacia do Ribeirão Tijuco Preto (SP). 
Outro condicionante antropogênico averiguado a partir da Carta de Uso da Terra (figura 7), que dinamiza os processos erosivos, interferindo na dinâmica do escoamento fluvial, condiz com a urbanização da cidade de Rio das Pedras. O canal principal do Ribeirão Tijuco Preto atravessa a cidade a qual ocupa longitudinalmente boa extensão de seu curso. Verifica-se neste setor que a referida drenagem encontra-se canalizada, sendo que o setor urbano ocupa as faixas marginais de Áreas de Preservação Permanente (APPs), o que provoca alterações na dinâmica fluvial.

Esta canalização altera o nível de base local, promovendo a ativação da erosão regressiva, registrada em processos erosivos observados "in loco", bem como na Carta Geomorfológica, já que os canais de primeira ordem do setor de nascentes estão margeados por rupturas de declive, entalhados em anfiteatros com processos regressivos atuantes.

Dessa forma, verifica-se que, os canais de primeira ordem estão entalhados em forma de "V", caracterizando o processo erosivo longitudinal, regredindo o setor de nascentes; enquanto os cursos principais, apresentam-se em formas de fundo plano, registrando nas margens fluviais, conforme pode-se observar na foto 1 , a ação de processos erosivos laterais, os quais assoream o canal de drenagem.

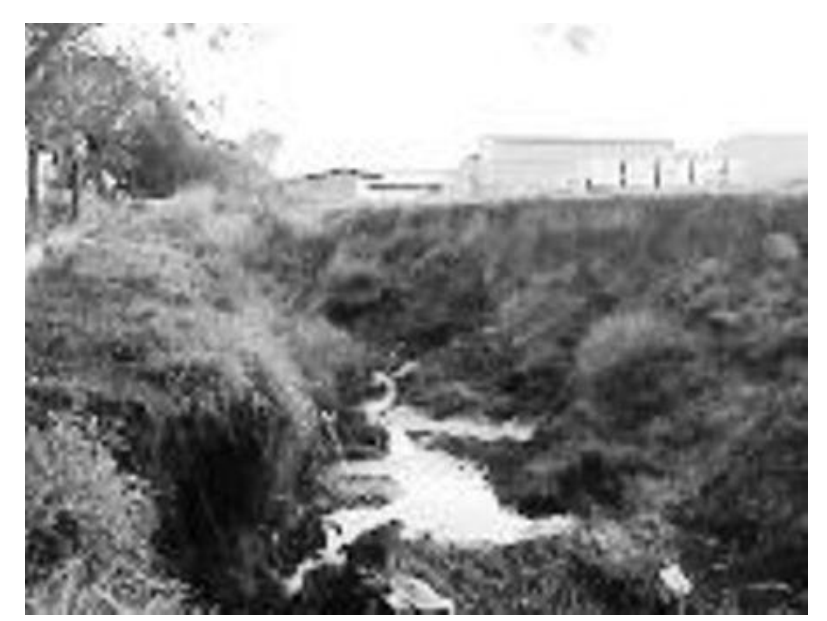

FOTO 1: Processos erosivos laterais na Alta Bacia do Ribeirão Tijuco Preto a montante do setor canalizado. Autor: Silveira, A. 


\section{Carta de Uso da Terra da Bacia do Ribeirão Tijuco Preto (SP)}

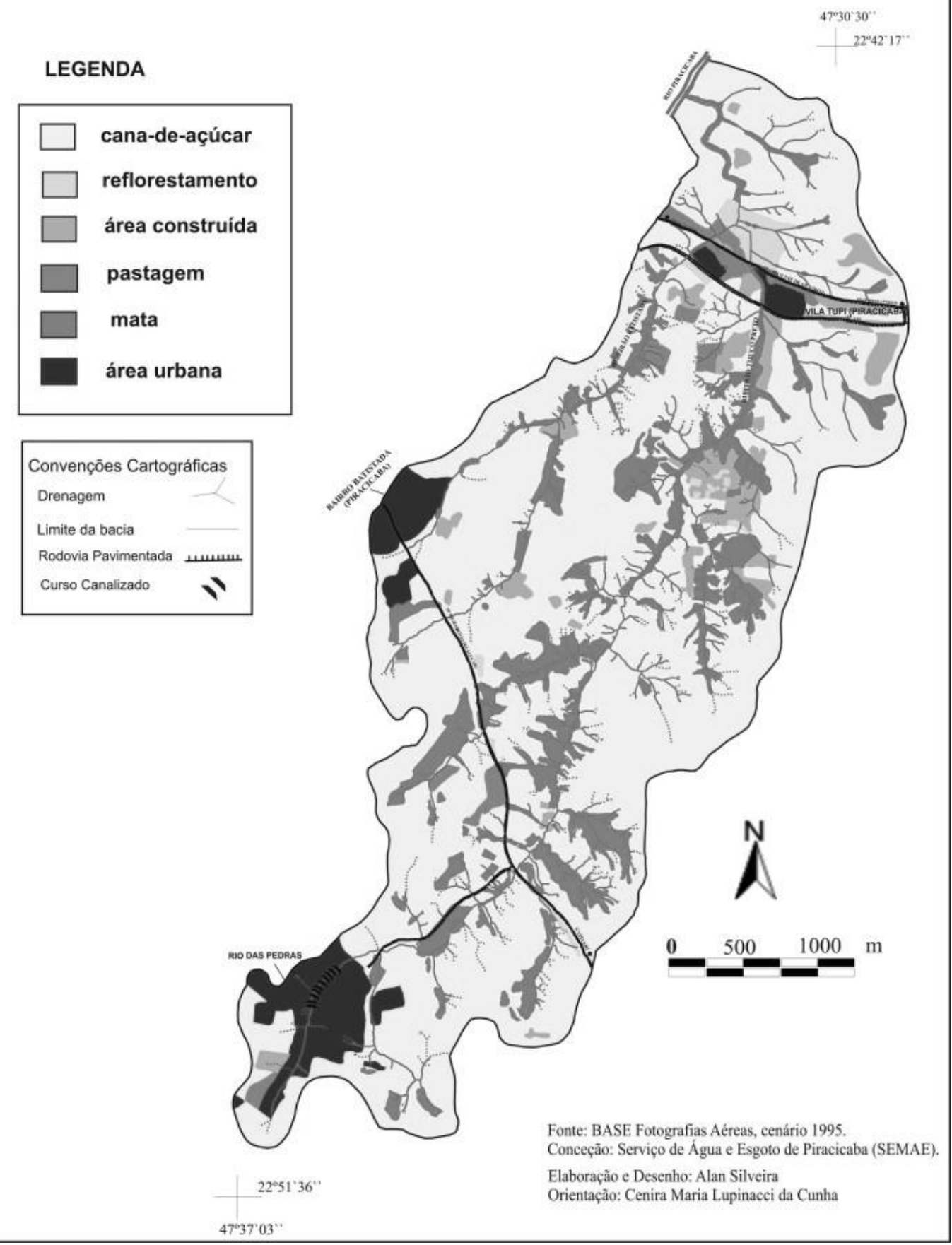

FIGURA 7: Carta de Uso da Terra da Bacia do Ribeirão Tijuco Preto (SP). 
O setor da Média Bacia foi o que apresentou resultados mais interessantes do ponto de vista geomorfológico, haja vista que a presença do extenso interflúvio sub-tabular entre o Ribeirão Tijuco Preto e o Ribeirão Batistada interfere diretamente na dinâmica morfológica da Bacia. Dessa forma, para efeito de melhor análise, este setor foi subdividido na Média Bacia Leste, que corresponde à área drenada pelo Ribeirão Tijuco Preto e a Média Bacia Oeste, representado pela Bacia do Ribeirão Batistada, como apresentado na Figura 5.

$\mathrm{Na}$ Média Bacia Leste, as formas de relevo encontram-se mais dissecadas, apresentando vertentes íngremes com interflúvios estreitos, registrando elevado número de canais de primeira ordem. Estes se encontram entalhados em "anfiteatros", buscando aprofundar seus leitos, tendo o fundo de vale em "V". As vertentes apresentam contínuas irregularidades e concavidades por sua extensão, estando margeadas e escalonadas por prolongadas rupturas de declive. Nestas, são encontradas processos erosivos lineares que geram desde sulcos erosivos a voçorocamentos (Figura 6).

Tais processos são condicionados tanto pela ação antropogênica, como também pelas características litológicas e pedológicas da área, as quais denotam potencial erosivo pela presença, sobretudo, de Argissolos e Neossolos, marcados respectivamente pela diferença textural entre os horizontes $A$ e $B$, e pela baixa expressão dos processos pedogenéticos, além do substrato litológico representado pelos arenitos da Formação Itararé. Já a ação antrópica está representada pelo uso da terra (Figura 7) predominantemente vinculado a monocultura canavieira, bem como pela presença, na transição com o setor da Baixa Bacia, do distrito de Piracicaba denominado por Vila Tupi, ocupando área de APP, no fundo de vale do Ribeirão Tijuco Preto.

Nestes termos, registra-se para o setor da Média Bacia Leste a presença marcante de formas erosivas em áreas dominantemente canavieiras, as quais 
seus solos de potencial erosivo, permanecem expostos à ação do escoamento pluvial, conforme demonstra a foto 2 .

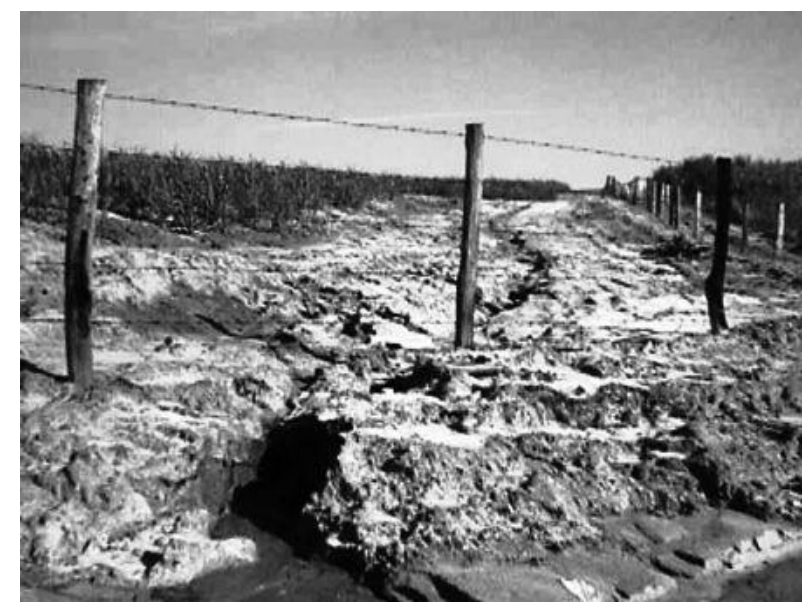

FOTO 2: Processo erosivo linear em área canavieira da Média Bacia Leste. Autor: Silveira, A.

Já no setor da Média Bacia Oeste, representado pela Bacia do Ribeirão Batistada, as vertentes apresentam-se suavizadas e convexas, registrando interflúvios extensos, sobretudo na alta Bacia do Ribeirão Batistada. Já na baixa e média Bacia do Ribeirão Batistada, registram-se uma quantidade significativa de canais de primeira ordem, elevando a dissecação do relevo, encontrando-se um maior número de anfiteatros margeados por rupturas topográficas (Figura 6).

Assim, o setor da Média Bacia Oeste apresenta, na alta Bacia do Ribeirão Batistada, conforme constatado na Carta de Uso da Terra e em trabalhos de campo, a presença da monocultura canavieira tomando todo o interflúvio e as cabeceiras de drenagem deste curso fluvial, intensificando os processos erosivos, conforme aferido na Carta Geomorfológica. Outros condicionantes aos processos erosivos no setor da alta Bacia do Ribeirão Batistada, condizem com a área urbana de Piracicaba, instalada no extremo oeste desta Bacia com o bairro Batistada, margeando a vertente do canal de drenagem, retirando por completo a mata ciliar. 
De modo geral, na alta Bacia do Ribeirão Batistada, embora os condicionantes morfológicos não sejam favoráveis ao desencadeamento de processos erosivos, os mesmos não deixam de existir, já que o condicionante antropogênico, associado ao litológico, pela presença de intercalações de calcário e folhelho, bem como ao climático, pela concentração e intensidade de chuvas no verão, desencadeiam tais processos, pontuados na Carta Geomorfológica por rupturas topográficas e sulcos erosivos.

Diferentemente, na média e baixa Bacia do Ribeirão Batistada os fatores morfológicos denotam relevos mais íngremes e dissecados, com potencial elevado a processos morfológicos. Encontram-se nas vertentes, paralelamente ao curso fluvial principal e margeando os canais de primeira ordem, rupturas topográficas associadas a processos erosivos lineares, conforme demonstrado na Carta Geomorfológica.

Estes processos, além dos condicionantes morfológicos, vinculam-se também ao uso e ocupação da terra por meio da cana-de-açúcar, acompanhada por represamentos dos canais de primeira ordem em pequenas propriedades (foto 3). Os canaviais estão em parte do ano desprovidos de cobertura vegetal, como também estão sujeitos permanentemente ao revolvimento de seus solos para aragem, ficando expostos e susceptíveis as ações do escoamento pluvial. Já os represamentos, alteram o nível de base local, provocando a retomada erosiva a montante, influenciando diretamente na dinâmica do escoamento fluvial.

Outro condicionante antropogênico é exemplificado pela ocupação do bairro Jardim Bartira, pertencente à Piracicaba, em área de preservação permanente (APP) da baixa Bacia do Ribeirão Batistada, desprovendo-a de cobertura vegetal. Além das intervenções humanas citadas somam-se ainda, no agravo das potencialidades ao desencadeamento de processos erosivos na baixa e média Bacia do Ribeirão Batistada, os condicionantes pedológicos, com a presença dos Argissolos e Neossolos. Os Argissolos apresentam significativa diferença textural entre os horizontes $A$ e $B$, enquanto os Neossolos caracterizam-se pela pouca 
espessura com pequena expressão dos processos pedogenéticos, implicando em alta fragilidade erosiva.

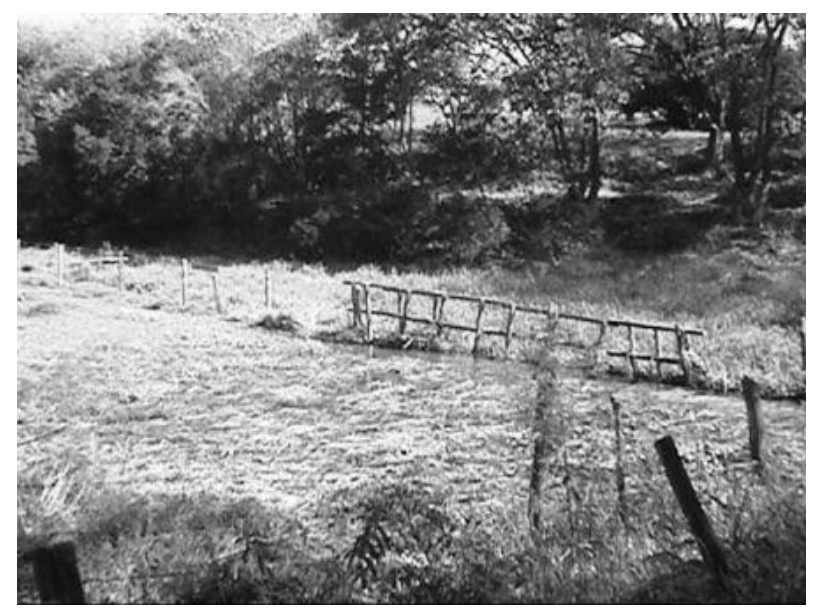

FOTO 3: Represamento de canal de primeira ordem do Ribeirão Batistada na Média Bacia Oeste. Autor: Silveira, A.

Por fim, o setor da Baixa Bacia apresenta canais de primeira ordem, entalhados em morfologia concavizada, com interflúvios estreitos, sobretudo na margem direita, cujas vertentes encontram-se íngremes, suavizando-se progressivamente de acordo com a proximidade do nível de base do Tijuco Preto, representado pelo Rio Piracicaba. Tais resultados, potencialmente favoráveis ao desencadeamento de processos morfológicos, ainda são agravados pela ação antrópica, bem como pelos condicionantes litológicos, pedológicos e climáticos.

O condicionante antropogênico é representado de maneira expressiva pelo cultivo da monocultura canavieira, sendo que o material pedogenético é representado pelos Argissolos e Neossolos com elevado potencial erosivo, enquanto o substrato litológico é caracterizado pelos arenitos da Formação Itararé. A foto 4 ilustra a dinâmica apontada, com um processo erosivo instalado em via canavieira direcionada perpendicularmente ao canal fluvial, formado pela concentração de águas pluviais, com registro marcante de material arenítico transportado. 
A tabela a seguir (tabela 1), sintetiza as principais informações discutidas em cada compartimento morfológico da Bacia do Ribeirão Tijuco Preto.

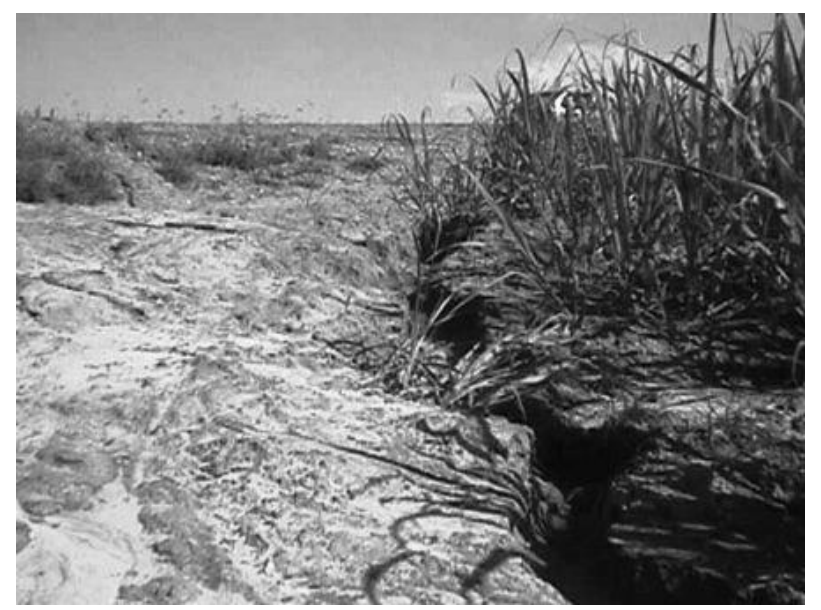

FOTO 4: Erosão linear em área canavieira na Baixa Bacia. Autor: Silveira, A. 
RA'E GA 21 (2010), p. 365-391

\begin{tabular}{|c|c|c|c|c|c|}
\hline & GEOLOGIA & SOLOS & GEOMORFOLOGIA & USO DA TERRA & CONDIÇÕES EROSIVAS \\
\hline ALTA BACIA & $\begin{array}{l}\text { Predomínio das } \\
\text { Formações Tatuí e } \\
\text { Botucatu }\end{array}$ & $\begin{array}{l}\text { Nitossolos e } \\
\text { Latossolos }\end{array}$ & $\begin{array}{c}\text { Apresenta colinas de topos } \\
\text { convexos, estando as nascentes } \\
\text { entalhadas em formas concavizadas, } \\
\text { semelhantes a "anfiteatros" }\end{array}$ & $\begin{array}{l}\text { Áreas canavieiras; } \\
\text { Urbanização da cidade } \\
\text { de Rio das Pedras }\end{array}$ & $\begin{array}{l}\text { Áreas canavieiras com } \\
\text { processos erosivos lineares; } \\
\text { Nos canais de primeira ordem } \\
\text { registram-se processos } \\
\text { erosivos longitudinais; nos } \\
\text { cursos principais, registram-se } \\
\text { nas margens fluviais, a ação de } \\
\text { processos erosivos laterais, os } \\
\text { quais assoream o canal de } \\
\text { drenagem. }\end{array}$ \\
\hline $\begin{array}{l}\text { MÉDIA BACIA } \\
\text { LESTE }\end{array}$ & Formação Itararé & $\begin{array}{l}\text { Argissolos e } \\
\text { Neossolos }\end{array}$ & $\begin{array}{c}\text { As formas de relevo encontram-se } \\
\text { dissecadas, apresentando vertentes } \\
\text { íngremes com interflúvios estreitos, } \\
\text { registrando elevado número de } \\
\text { canais de primeira ordem. Estes se } \\
\text { encontram entalhados em } \\
\text { "anfiteatros", buscando aprofundar } \\
\text { seus leitos, tendo o fundo de vale em } \\
\text { "V" }\end{array}$ & $\begin{array}{l}\text { Uso da terra } \\
\text { predominantemente } \\
\text { vinculado a monocultura } \\
\text { canavieira, bem como a } \\
\text { presença, na transição } \\
\text { com o setor da Baixa } \\
\text { Bacia, do distrito de } \\
\text { Piracicaba denominado } \\
\text { por Vila Tupi }\end{array}$ & $\begin{array}{l}\text { As vertentes apresentam } \\
\text { contínuas irregularidades e } \\
\text { concavidades por sua } \\
\text { extensão, estando margeadas } \\
\text { e escalonadas por prolongadas } \\
\text { rupturas de declive. Nestas, } \\
\text { são encontrados processos } \\
\text { erosivos lineares que geram } \\
\text { desde sulcos erosivos a } \\
\text { voçorocamentos. } \\
\end{array}$ \\
\hline $\begin{array}{c}\text { MÉDIA BACIA } \\
\text { OESTE }\end{array}$ & $\begin{array}{l}\text { Predomínio das } \\
\text { Formações Itararé } \\
\text { e Irati }\end{array}$ & $\begin{array}{c}\text { Argissolos e } \\
\text { Neossolos }\end{array}$ & $\begin{array}{l}\text { As vertentes apresentam-se } \\
\text { suavizadas e convexas, registrando } \\
\text { interflúvios extensos, sobretudo na } \\
\text { alta Bacia do Ribeirão Batistada. Já } \\
\text { na baixa e média Bacia do Ribeirão } \\
\text { Batistada, registram-se uma } \\
\text { quantidade significativa de canais de } \\
\text { primeira ordem, elevando a } \\
\text { dissecação do relevo, encontrando- } \\
\text { se um maior número de anfiteatros } \\
\text { margeados por rupturas topográficas }\end{array}$ & $\begin{array}{l}\text { Ocupação da terra por } \\
\text { meio da cana-de-açúcar, } \\
\text { acompanhada por } \\
\text { represamentos nos } \\
\text { canais de primeira ordem } \\
\text { em pequenas } \\
\text { propriedades; } \\
\text { Bairro Batistada e } \\
\text { Bairro Jardim Bartira, } \\
\text { ambos pertencentes à } \\
\text { Piracicaba } \\
\end{array}$ & $\begin{array}{l}\text { Encontram-se nas vertentes, } \\
\text { paralelamente ao curso fluvial } \\
\text { principal e margeando os } \\
\text { canais de primeira ordem, } \\
\text { rupturas topográficas } \\
\text { associadas a processos } \\
\text { erosivos lineares }\end{array}$ \\
\hline BAIXA BACIA & Formação Itararé & $\begin{array}{l}\text { Argissolos e } \\
\text { Neossolos }\end{array}$ & $\begin{array}{c}\text { Apresenta canais de primeira ordem, } \\
\text { entalhados em morfologia } \\
\text { concavizada, com interflúvios } \\
\text { estreitos, sobretudo na margem } \\
\text { direita, cujas vertentes encontram-se } \\
\text { íngremes }\end{array}$ & $\begin{array}{l}\text { Representado de } \\
\text { maneira expressiva pelo } \\
\text { cultivo da monocultura } \\
\text { canavieira }\end{array}$ & $\begin{array}{l}\text { Processos erosivos instalados } \\
\text { em áreas canavieiras }\end{array}$ \\
\hline
\end{tabular}

TABELA 1: Principais Informações discutidas por compartimentos morfológicos da Bacia do Ribeirão Tijuco Preto. Organização: Silveira, A. 


\section{CONSIDERAÇÕES FINAIS}

Diante da abordagem sistêmica, ao analisar as informações obtidas através dos produtos cartográficos referentes à geomorfologia e ao uso da terra, associados aos dados encontrados na bibliografia e em trabalhos de campo, foi possível realizar um diagnóstico das condições de relevo, associado, sobretudo ao desencadeamento de processos erosivos, que pode servir como subsídio ao planejamento ambiental da Bacia de estudo.

A Carta Geomorfológica de detalhe permitiu a análise e a espacialização das formas de relevo e, dedutivamente, dos processos atuantes na superfície terrestre. Foram mapeados dados relativos à drenagem, modelados de entalhe, linhas de cumeadas, formas de vertentes, feições localizadas, bem como os modelados e alterações antrópicas na topografia. A análise conjunta destas formas, associadas às informações litológicas, pedológicas e climáticas, permitiu a compreensão dos processos atuantes no relevo.

A estas informações foram associadas aquelas registradas na Carta de Uso da Terra, que espacializou as informações referentes ao uso e ocupação derivados da produção humana, contribuindo significativamente para uma melhor análise dos processos morfológicos atuantes no relevo, bem como os padrões de organizações espaciais derivados da relação entre o sistema natural e o sistema antrópico.

De forma geral, a análise dos produtos cartográficos elaborados, permitiu constatar que a Bacia do Ribeirão Tijuco Preto vem sofrendo o desencadeamento de processos erosivos variados, vinculados principalmente a processos erosivos lineares acelerados, cujas formas foram mapeadas em grande número, principalmente sulcos erosivos, ravinamentos e voçorocamentos, além de inúmeras rupturas de declive.

Tais processos estão associados a uma conjunção de condicionantes, que podem ser apontados pelas fragilidades representadas muitas vezes pelas litologias aflorantes, associados as fragilidades representadas pelas tipologias dos solos, além do clima marcado pelos altos índices pluviométricos de verão, bem como, e, de maneira significativa, pela intervenção humana.

O condicionante antrópico está majoritariamente representado pela monocultura canavieira e pela urbanização, sendo agentes cruciais no desencadeamento dos processos erosivos existentes e na interferência direta na dinâmica do escoamento fluvial e pluvial da 
Bacia do Ribeirão Tijuco Preto. Têm-se, dessa forma, características inerentes ao quadro natural, muitas vezes favoráveis ao desencadeamento de processos morfológicos, sendo agravadas e dinamizadas pela atuação do condicionante humano.

\section{REFERÊNCIAS BIBLIOGRÁFICAS.}

ALMEIDA, F.F.M. Fundamentos Geológicos do Relevo Paulista. Boletim do Instituto Geográfico Geológico. São Paulo, n.41, p. 167-263, 1964.

CHIRSTOFOlETTI, A. Análise de Sistemas em Geografia. São Paulo: HUITEC, 1979.

CHRISTOFOLETTI, A. A Aplicabilidade do Conhecimento Geomorfológico nos Projetos de Planejamento. In: GUERRA, A.J.T.; CUNHA, S.B.C (Org.). Geomorfologia - Uma Atualização de Bases e Conceitos. Rio de Janeiro: Bertrand Brasil, 1995.

CHRISTOFOlETTI, A. Modelagem de Sistemas Ambientais. São Paulo: Edgard Blucher, 1999.

CHORLEY, R.J.; KENNEDY, B.A. Physical Geography: a systems approach. Londres: Prentice Hall, 1971.

CUNHA, C.M.L. A Cartografia do Relevo no Contexto da Gestão Ambiental. 2001. Tese (Doutorado em Geociências e Meio Ambiente) - Instituto de Geociências e Ciências Exatas, Unesp, 2001.

CUNHA, C.M.L; MENDES, I.A.; SANCHEZ, M.C.I. A Cartografia do Relevo: Uma Análise Comparativa de Técnicas para a Gestão Ambiental. Revista Brasileira de Geomorfologia, Uberlândia, ano 4, n. 1, p. 01-09, 2003a.

CUNHA, C.M.L; MENDES, I.A.; SANCHEZ, M.C. Técnicas de Elaboração, Possibilidades e Restrições de Cartas Morfométricas na Gestão Ambiental. Geografia, Rio Claro, v.28, n. 3, p. 415-429, 2003b.

DEFFONTAINES, P. Regiões e paisagens do Estado de São Paulo. Primeiro esboço de divisão regional. Geografia, São Paulo, ano 1, n.2, p.117-169, 1935.

EMBRAPA, EMPRESA BRASILEIRA DE PESQUISA AGROPECUÁRIA. Sistema Brasileiro de Classificação dos Solos. Brasília: DF, 1999.

IF, INSTITUTO FLORESTAL. Plano de manejo da Estação Experimental de Tupi Piracicaba, SP. Série Registros, São Paulo, n.19, p.1-61, 1999.

IGG, INSTITUTO GEOGRÁFICO E GEOLÓGICO DO ESTADO DE SÃO PAULO. Folha Geológica de Piracicaba (SF 23-M 300), escala 1:100.000, 1966.

IAC, INSTUTO AGRONÔMICO DE CAMPINAS. Carta Pedológica Semi-Detalha do Estado de São Paulo: Folha de Piracicaba (SF.23-Y-A-IV), escala 1:100.000, 1989. 
IPT, INSTITUTO DE PESQUISA TECNOLÓGICA. Mapa Geomorfológico do Estado de São Paulo. São Paulo: IPT, 1981 a.

IPT, INSTITUTO DE PESQUISA TÉCNOLÓGICA. Mapa Geológico do Estado de São Paulo. São Paulo: IPT, 1981 b.

MATTOS, S.H.V.L. de; PEREZ FILHO, A. Complexidade e Estabilidade em Sistemas Geomorfológicos: uma introdução ao tema. Revista Brasileira de Geomorfologia. Goiânia, ano 5, n.1, p.11-18, 2004.

PENTEADO, M.M. Geomorfologia do Setor Centro-Ocidental da Depressão Periférica. São Paulo: IGEOG/USP, 1976. (Série Teses e Monografias, n.22).

PROCHNOW, M.C.R. Análise Ambiental da Sub-Bacia do Rio Piracicaba: Subsídio ao seu Planejamento e Manejo. Tese (Doutorado e Geografia) - Instituto de Geociências e Ciências Exatas, Unesp, 1994.

ROSS, J.L.S. Ecogeografia do Brasil: Subsídio para Planejamento Ambiental. São Paulo: Oficina de Textos, 2006.

SILVA, D.A.; PFEIFER, R.M. Zoneamento de Uso das Terras da Estação Experimental de Tupi-SP. Revista do Instituto Florestal, São Paulo, v.10, n. 1, p. 23-38, 1998.

TRICART, J. Principes et Méthodes de la Geomorphologie. Paris: Masson et Cie, 1965.

VERSTAPEN, H.T.; ZUIDAM, R.A. Van ITC System of Geomorphological Survey. Netherlands, Manuel ITC Textbook, Vol. VII, Chapter VII, 1975.

VICENTE, L.E; PEREZ FILHO, A. Abordagem Sistêmica em Geografia. Geografia. Rio Claro, v.28, n.3, p. 323-344, 2003. 